\title{
Analysis and stability test of the extracts from Ulmus parvifolia leaves
}

\author{
Doo-Young Kim ${ }^{1} \cdot$ Soobin Song ${ }^{1} \cdot$ Iljoo Kim $^{1} \cdot$ Se-Kyoo Jeong ${ }^{2} \cdot$ Sungwoo Kim $^{2}$ \\ $\cdot$ Jung-Hee Kim ${ }^{1} \cdot$ Hyun-Jae Jang ${ }^{1} \cdot$ Sei-Ryang $\mathrm{Oh}^{1} \cdot$ Hyung Won Ryu ${ }^{1}$ iD
}

\section{참느릅나무(Ulmus parvifolia) 잎 추출물 분석 및 안정성 평가}

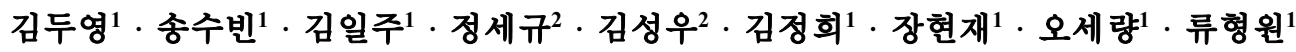

Received: 28 October 2020 / Accepted: 6 November 2020 / Published Online: 31 December 2020

(C) The Korean Society for Applied Biological Chemistry 2020

\begin{abstract}
A simple and reliable HPLC method was developed to determine pharmacologically standard marker compounds of Ulmus parvifolia leaves. Standard markers were characterized with neochlorogenic acid (trans-5-O-caffeoylquinic acid, 5-CQA) and chlorogenic acid (trans-3-O-caffeoylquinic acid, 3-CQA) using NMR and UPLC-QTof-MS analysis. A method for qualitative/ quantitative analysis of the leaves extracts were evaluated including two compounds by using HPLC. The stability test of $30 \%$ ethanolic extracts of the leaves sample and standard markers have been evaluated for six months. However, no significant changes in the content of the marker compounds of each extract was observed during the time of investigation.
\end{abstract}

Keywords Caffeoylquinic acid - Stability · Ulmus parvifolia leaves · Ultra high performance liquid chromatography

Hyung Won Ryu $(\bowtie)$

E-mail:ryuhw@kribb.re.kr

${ }^{1}$ Natural Medicine Research Center, Korea Research Institute of Bioscience and Biotechnology, 30, Yeongudanji-ro, Ochang-eup, Cheongwon-gu, Cheongju-si, Chungcheongbuk-do 28116, Republic of Korea

${ }^{2}$ Research Division, Incospharm Corporation, Daejeon 34036, Republic of Korea

This is an Open Access article distributed under the terms of the Creative Commons Attribution Non-Commercial License (http://creativecommons. org/licenses/by-nc/3.0/) which permits unrestricted non-commercial use, distribution, and reproduction in any medium, provided the original work is properly cited.

\section{서 론}

품질 표준화는 전 세계 의약, 건강기능식품, 화장품 산업에서 강조되고 있다. 미국의 세계 보건기구(WHO)와 식품의약국(FDA) 는 품질 표준화에 대한 강화 된 지침을 발표했다. 천연물소재 의 품질 표준화는 품질, 효능, 재현성을 보장하기 위해 일정한 구성, 정성, 정량 값과 관련된 방법을 설정하는 절차이다[1]. 천 연물소재는 많은 성분으로 구성되어 있으며 다양한 기능을 가 지고 있다. 특히, 식물의 생육 조건인 성장, 수확 시간, 기후조 건 등과 같은 다양한 요인으로 인한 변동성은 천연물소재의 질 적 및 정량적 값에 영향을 미칠 수 있고 따라서 품질 표준화가 중요하다[2]. 품질 표준화 절차를 통해 통제된 요소에서 잘 정 의되고 일관된 천연물소재의 구성은 고품질의 의약, 건강기능식 품, 화장품의 개발 및 생산에 가장 중요한 항목이며, 천연물 관 련 전반적인 산업에서의 생존과 성공은 일정한 품질을 보장하 는 것이 선택이 아닌 필수조건이다[3].

식품의약품안전처에서 규격을 설정하여 관리하고 있으며, 생 약은 대한약전 130 종과 생약규격집 381종으로 총 511종의 한 약재가 수재되어 있지만 품질 표준화 연구는 아직 미흡한 실정 이다[4]. 특히, 국내 천연물 소재 산업 시장은 전통적으로 사용 가능한 다양한 한약재 외에도 생약들과 자생식물들이 존재하고 이를 이용한 의약, 건강기능성식품, 화장품들의 원료소재 형태 로 유통되어 사용되고 있어 보다 과학적이고 체계적인 품질 표 준화 평가자료 확보가 절실히 필요하다[5].

참느릅나무(Ulmus parvifolia) 잎은 느릅나무과(Ulmaceae)의 잎으로 주로 한국, 중국, 대만, 일본에 주로 서식하고 한방에서 는 느릅나무과의 나무 또는 뿌리 껍질(유근피)을 약용 부위로 쓰며 이뇨, 청열, 해독, 배농 작용 등이 보고된 중요한 약재이 다[6]. 뿌리 껍질 효능의 주요성분으로 catechin, catechin glycosides, sesquiterpene $O$-naphthoquinones, lignan, neolignan glycosides 등이 알려져 있고[7-10] 최근 과학적인 효능 규명 연 
구로 항산화, 항염증, 항알러지, 항암, 항바이러스, 심혈관계질환 보호 효과 결과들이 보고 되어 있다[11-15]. 대부분 선행연구는 유근피 중심으로 다양한 생리활성과 많은 화합물들을 분리 보 고하였지만 느릅나무 잎에 대한 연구는 미흡하게 나타났다.

본 연구는 느릅나무 잎을 보다 적절한 품질 지표로 구성 요 소를 제시하고 천연물 소재로써 의약, 건강기능식품, 화장품의 품질표준화에 도움이 될 수 있는 최적의 분석 조건과 안정성 정보를 제공하며, 확립된 품질 관리 방법을 통해 전략적 생산 에 적용될 수 있음을 확인하고자 하였다.

\section{재료 및 방법}

\section{실험 재료}

본 연구에 사용된 참느릅나무 잎 $10 \mathrm{~kg}$ 을 합천생약가공 영농조 합법인에서 수집한 시료를 구매하여 한국생명공학연구원 해외 생물소재센터 백진협 박사(International Biological Material Research Center, Korea Research Institute of Bioscience and Biotechnology, Daejeon, Korea)의 분류 동정을 거쳐 선별하였 고 선정된 증거 표본은 한국생명공학연구원 해외생물소재센터 표본실에 보관하였다(KRIB 0085027).

\section{시약 및 기기}

Ethanol $(\mathrm{EtOH})$ 용매(SK chemical, KR)는 추출물 제조를 위해 사용하였으며, 타겟 화합물 분석과 분리를 위해 high performance liquid chromatography (HPLC)용 methanol (MeOH, Honeywell, Moris Plains, NJ, USA)과 acetonitrile (ACN, Honeywell, Moris Plains, NJ, USA), tifluoroacetic acid (TFA, Tokyo Chemical Industries, Co., Ltd., Japan), formic acid (Sigma-Aldrich, St. Louis, MO, USA), leucine enkephalin (Sigma-Aldrich, USA)를 사용하여 ultraperformance liquid chromatography quadrupole time-of-flight mass spectrometry (UPLC-QTof-MS, Waters, Milford, MA, USA), photodiode array (PDA, Waters, Milford, MA, USA), HPLC (Agilent Technologies, Santa Clara, CA, USA), preparative-HPLC (PLC, Gilson, Middleton, WI, USA) 기기를 이용하여 진행하 였다. 구조분석을 위해 Bruker AM400 ( ${ }^{1} \mathrm{H}$ NMR $400 \mathrm{MHz}$, ${ }^{13} \mathrm{C}$ NMR $100 \mathrm{MHz}$, Billerica, MA, USA)에 methanol- $d_{4}$ (Cambridge Isotope Laboratories, Andover, MA, USA)를 사용 하여 분석하였다.

\section{참느릅나무 잎 추출물 제조 및 분리}

동결건조(CleanVac 8 Hanil Science Medical, Daejeon, Korea) 한 참느릅나무 잎 $100.0 \mathrm{~g}$ 을 다목적 분쇄기(DSMP-370, Korea) 를 이용하여 잘게 분쇄하였다. 그 중 $100.0 \mathrm{mg}$ 잎 시료에 $30 \%$ ethanol $(\mathrm{v} / \mathrm{v})$ 을 가하여 25 와 $50^{\circ} \mathrm{C}$ 에서 $1,3,5$ 시간 3 회 반복 추출(SDN-900H, SD Ultrasonic Cleaner, Seoul, Korea, $40 \mathrm{kHz}$, 주기당 15 분 추출과 15 분 대기로 3 주기 반복)한 후 여과하여 얻어진 여액을 감압 농축하여 최적 추출 조건을 확인하였다. 지 표성분 분리를 위해 $10 \mathrm{~kg}$ 을 (주)삼우다연 GMP 시설에 의뢰하 여 원물 10 배의 $30 \%$ 주정 $(\mathrm{v} / \mathrm{v})$ 으로 $50{ }^{\circ} \mathrm{C}$ 에서 3 시간 2 회 반복 추출한 후 $21.6^{\circ} \mathrm{Brix}$ 로 농축 하였다. 얻어진 느릅나무 잎 추출
물을 한국생명공학연구원 정읍 분원 생물공정지원팀에 동결건 조(50 L PVTFD 50R, 일신)로 농축 하였다(약 $1.72 \mathrm{~kg}$, 수율 $17.2 \%)$. 개방형 칼럼 $(80 \times 15 \mathrm{~cm})$ 분취 방법으로 확보된 느릅나 무 잎 유효분획물 2번을 prep-HPLC (PLC, Gilson, Middleton, $\mathrm{WI}, \mathrm{USA})$ 에 Atlantis T3 $\mathrm{OBD}(5 \mathrm{~mm}, 250 \times 19 \mathrm{~mm})$ 칼럼을 사용하여 (A)는 $0.1 \%$ TFA (tifluoroacetic acid) 증류수로 (B) 는 $0.1 \% \mathrm{TFA} \mathrm{CH}_{3} \mathrm{CN}$ 의 혼합 용매를 이동상으로 하는 $0.0-4.0$ $\min 5 \%$ (B), 4.0-23.0 $\min 5-13 \%$ (B), 23.0-40.0 $\min 13-17 \%$ (B), $40.0-41.0 \mathrm{~min} 17-90 \%$ (B), $41.0-50.0 \mathrm{~min} 90 \%$ (B), $50.0-$ $51.0 \mathrm{~min} 90-5 \%$ (B) 조건으로 UP Fr. 2-3-3 (neochlorogenic acid, trans-5-O-caffeoylquinic acid), UP Fr. 2-3-5 chlorogenic acid (trans-3-O-caffeoylquinic acid)를 각각 30.7 및 $108.0 \mathrm{mg}$ 분리하였다.

\section{UPLC-QTof-MS 및 PDF 분석 조건}

느릅나무 잎 지표 물질의 정성분석을 위해 UPLC-QTof-MS와 $\mathrm{PDA}$ 분석은 $\mathrm{BEH}_{18}(2.1 \times 100 \mathrm{~mm}, 1.7 \mu \mathrm{m})$ 칼럼 관과 $\mathrm{PDA}$ (photodiode array)와 mass를 장착한 UPLC에 유속 $0.4 \mathrm{~mL} /$ $\min$, 용매는 $0.1 \%$ formic acid가 포함된 증류수(A)와 $\mathrm{ACN}$ (B)을 사용하여 수행하였다. UPLC 이동상의 용매 조성은 0.0$1.0 \mathrm{~min} \quad 1 \% \quad$ (B), $1.0-3.0 \mathrm{~min} \quad 1-15 \% \quad$ (B), 3.0-11.0 min $15-$ $40 \%$ (B), $11.0-13.0 \mathrm{~min} \quad 40 \%$ (B), 13.1-15.0 min 40-1\% (B) 조건을 이용하였으며, 시료는 $2 \mu \mathrm{L}(1 \mathrm{mg} / \mathrm{mL})$ 주입하여 분석을 실시하였다.

\section{구조분석}

생리활성물질의 구조를 동정하기 위하여 $\mathrm{NMR}, \mathrm{MS}, \mathrm{UV}$ 등의 분광학적인 기기를 사용하였다. 먼저, ${ }^{1} \mathrm{H}-,{ }^{13} \mathrm{C}-\mathrm{NMR}$ 에서 수소 와 탄소의 개수와 chemical shift 값으로 기본적인 골격을 예상 하였고, 2D-NMR (COSY, HMQC, HMBC, DEPT)에서 수소탄소의 연관관계를 통해 치환기의 정확한 위치와 탄소 차수를 확인하여 물질의 구조를 확인하였고 선행문헌의 화합물과 비교 확인하여 구조를 결정하였다[16].

\section{Chlorogenic acid (3-O-caffeoylquinic acid)}

${ }^{1} \mathrm{H}$ NMR (500 MHz, methanol- $d_{4}, \delta$ ): 7.58 (d, $\left.J=16.0 \mathrm{~Hz}, 1 \mathrm{H}\right)$, 7.04 (d, $J=2.0 \mathrm{~Hz}, 1 \mathrm{H}), 6.94$ (dd, $J=8.2,2.0 \mathrm{~Hz}, 1 \mathrm{H}), 6.78$ (d, $J=8.2 \mathrm{~Hz}, 1 \mathrm{H}), 6.30$ (d, $J=16.0 \mathrm{~Hz}, 1 \mathrm{H}), 5.36$ (brd, 1H), 4.14 (m, $1 \mathrm{H}), 3.65(\mathrm{~m}, 1 \mathrm{H}), 1.932 .22(\mathrm{~m}, 4 \mathrm{H}) \mathrm{ppm} ;{ }^{13} \mathrm{C} \mathrm{NMR}(125 \mathrm{MHz}$, methanol- $\left.d_{4}, \delta\right)$ : $178.4,168.9,149.5,147.1,146.8,127.8,123.0$, $116.5,115.3,115.2,77.3,73.9,72.1,71.9,39.4,38.3$ ppm.

\section{Nochlorogenic acid (5-O-caffeoylquinic acid)}

${ }^{1} \mathrm{H}$ NMR (500 MHz, methanol- $d_{4}, \delta$ ): 7.56 (d, $\left.J=16.0 \mathrm{~Hz}, 1 \mathrm{H}\right)$, 7.05 (d, $J=2.0 \mathrm{~Hz}, 1 \mathrm{H}), 6.95$ (dd, $J=8.2,2.0 \mathrm{~Hz}, 1 \mathrm{H}), 6.78$ (d, $J=8.2 \mathrm{~Hz}, 1 \mathrm{H}), 6.27$ (d, $J=16.0 \mathrm{~Hz}, 1 \mathrm{H}), 5.35$ (m, 1H), 4.18 (brd, $1 \mathrm{H}), 3.75(\mathrm{~m}, 1 \mathrm{H}), 2.042 .25(\mathrm{~m}, 4 \mathrm{H}) \mathrm{ppm} ;{ }^{13} \mathrm{C} \mathrm{NMR}(125 \mathrm{MHz}$, DMSO- $\left.d_{6}, \delta\right): 175.6,167.3,148.1,145.7,145.3,126.4,121.6$, $115.1,113.8,113.8,74.7,72.1,70.5,69.9,36.8,37.4$ ppm.

\section{정량 분석}

분석 시료의 제조 표준 물질인 3-O-caffeoylquinic acid와 5-O- 
caffeoylquinic acid의 각각의 농도를 $1000 \mathrm{ppm}$ 만들어 원심분리 후 상등액을 취하여 분석용 vial 에 담아 진행하였다. 정량 값 은 측정값의 피크면적을 검량선 $(\mathrm{y}=\mathrm{ax}+\mathrm{b})$ 식에 대입한 후 계 산식에 의해 산출하였다. 검량선은 $\mathrm{x}$ 축에 반복 수 및 분석 시 점을, $\mathrm{y}$ 축에 피크면적을 적용하여 최소자승법으로 산출 하였다. 평가 항목은 특이성, 직선성, 검출 한계, 정량 한계, 시료 잔류 의 5 가지 항목으로 평가하였다.

\section{장기 보존 안전성 시험}

느릅나무 잎 추출물과 표준 물질인 3-O-caffeoylquinic acid (chlorogenic acid)와 5-O-caffeoylquinic acid (neochlorogenic acid)를 상온에 0, 13 , 6개월 동안 methanol $(\mathrm{MeOH}$, Honeywell, Moris Plains, NJ, USA)에 용해하여 시험 물질의 안정성을 평 가하기 위하여 실시하였다. 장기 보존 시험의 조건은 온도 조 건 $25^{\circ} \mathrm{C}$, 상대습도 $40 \%$ 조건을 동시 처리 진행하였으며, 표준 물질의 각 농도를 $1000 \mathrm{ppm}$ 만들어 원심분리 후 상등액을 취 하여 분석용 vial에 담아 UPLC로 분석하였다. 시험은 2019년 12월 8일 개시하여 2020년 1월8일, 3월8일, 6월 8일 까지 0, $1,3,6$ 개월 간격으로 총 5 회 반복 3 회 실시하였다.

\section{가혹 조건 안전성 시험}

느릅나무 잎 추출물과 표준 물질인 3-O-caffeoylquinic acid와 5-O-caffeoylquinic acid의 가혹 시험 조건은 온도와 광에 대하 여 16 일간 처리하면서 개시일부터 2일 간격으로 methanol에 용 해하여 느릅나무 추출물에 포함된 지표 성분 2종을 UPLC로 분 석하여 가혹한 조건에서 안정성을 평가하기 위한 실험을 실시 하였다. 가혹 시험의 조건은 온도 $70{ }^{\circ} \mathrm{C}$ 일정하게 유지하여 진 행하였고 광 조건은 일반 직사광선이며, 시험은 2019년 12월 8 일 개시하여 2일 간격으로 총 9회 분석하였다.

\section{결과 및 고찰}

\section{분석 조건 확립}

최적의 분석 조건을 확립하기 위해 resolution과 overlapping으 로 정확하게 구현하기 위해 $\mathrm{ACN}$ 용매를 기본으로 하는 분석 조건을 확립하였다. 선행문헌을 통해 다양한 분석 조건을 검토 하였지만 목표로 하는 느릅나무 잎에 포함된 지표 성분 2종을 분석하기 위한 최적의 분석 조건은 확인되지 않았다[17-19]. 따 라서 반복적인 분석 조건 개발 및 검정을 통해 확립된 분석 조 건에서 크게 5 개의 peak를 검출할 수 있는 조건을 확인하였다 (Fig. 1). Peak들은 [M-H] $]^{-}$의 negative 모드에서 이온 형태로 $\mathrm{m} / \mathrm{z}$ (mass-to-charge ratio)의 $353\left(\mathrm{MS}^{2} 191\right), 353\left(\mathrm{MS}^{2} 191\right.$ ), $609\left(\mathrm{MS}^{2} 301\right), 463\left(\mathrm{MS}^{2} 301\right), 593\left(\mathrm{MS}^{2} 285\right)$ 값을 얻었 고 선행문헌, PubChem, ChemSpider 등의 정보를 비교하여 예 상화합물들로 확인하였다. 검출된 5개의 peak들은 매우 유사한 극성과 형태로 존재하여 상대적으로 산업적 활용성이 뛰어나며 쉽게 구할 수 있는 일반적인 2종의 성분을 선정하였다[20-21]. 느릅나무 잎 추출물에 포함된 지표 성분 2종을 순수 분리하여 $\mathrm{NMR}$ 을 이용한 구조 동정과 $\mathrm{MS}, \mathrm{MS}^{2}, \mathrm{HRMS}$ 성분 비교를 통 해 3-O-caffeoylquinic acid (chlorogenic acid)와 5-O-caffeoylquinic acid (neochlorogenic acid)임을 확인하였다.

\section{정량분석 결과}

특이성은 blank 시료를 측정하여 시험 물질의 retention time과 동일한 위치에서 간섭 피크의 유무를 확인하였으며 간섭 피크 가 없음을 확인하였다. 직선성은 표준 용액 $5-50 \mu \mathrm{g} / \mathrm{mL}$ 의 농도 를 각 1 회 측정하여, 표준 용액의 농도와 피크 면적의 결정 계 수를 산출하였고 판정기준은 결정 계수 $\mathrm{r}^{2}$ 이 0.998 이상인 것으 로 하였고 0.9983 으로 적합 하였다. 검출 한계는 검량선에 근

(A)

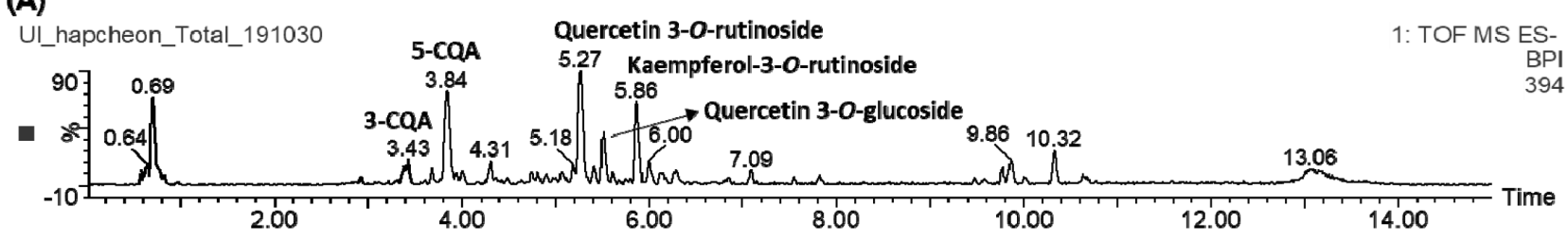

(B)
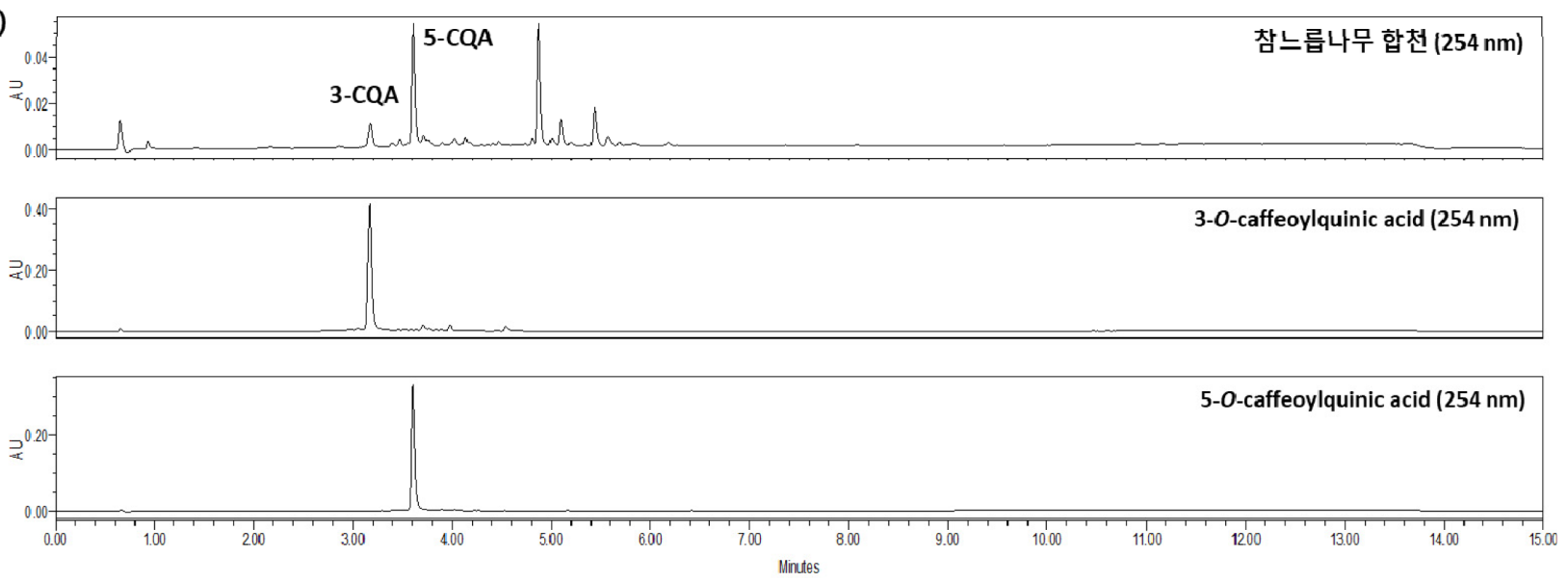

Fig. 1 UPLC-QTof-MS (A) and PDA chromatogram (B) of Ulmus parvifolia leaves extracts and two standard compounds 
Table 1 Validation of isolated compounds from Ulmus parvifolia leaves on UPLC-PDA

\begin{tabular}{cccccc}
\hline \hline Comp. & Range $\left(\mu \mathrm{g} \mathrm{mL} \mathrm{mL}^{-1}\right)$ & Linear model & Coefficient of determination & $\mathrm{LOD}^{\mathrm{b}}\left(\mu \mathrm{g} \mathrm{mL}{ }^{-1}\right)$ & $\mathrm{LOQ}^{\mathrm{c}}\left(\mu \mathrm{g} \mathrm{mL}{ }^{-1}\right)$ \\
\hline 3-CQA & $0-200$ & $\mathrm{y}=7030.2 \mathrm{x}-5868.9$ & 0.9995 & 0.19 & 0.57 \\
5-CQA & $0-200$ & $\mathrm{y}=6483 \mathrm{x}-5157.8$ & 0.9996 & 1.91 & 5.78 \\
\hline
\end{tabular}

${ }^{\mathrm{a}} \mathrm{y}=$ peak area, $\mathrm{x}=$ concentration of standard $\left(\mathrm{mg} \mathrm{mL}^{-1}\right)$

${ }^{\mathrm{b}}$ Coefficient of determination $\left(\mathrm{R}^{2}\right)$ is the square of the correlation coefficient

${ }^{c} \mathrm{LOD}$ and LOQ are the limits of detection and quantitation, respectively

For six points on the standard calibration curves, each concentration was injected three times on UPLC-PDA (254 nm)

(A)

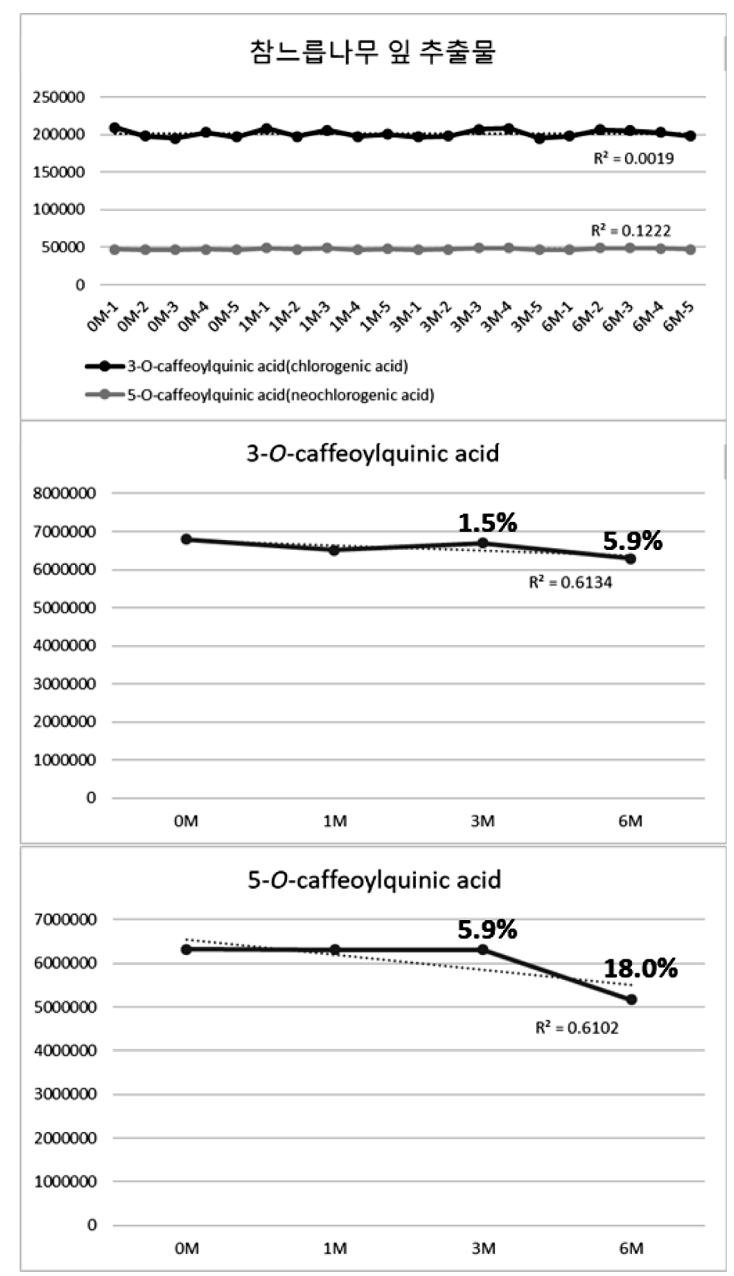

Fig. 2 Long-term storage stability results. (A) 3-O-caffeoylquinic acid and 5-O-caffeoylquinic acid contained in Ulmus parvifolia leaves extract. (B) Two standard compounds, 3-O-caffeoylquinic acid and 5-Ocaffeoylquinic acid

거한 표준편차와, 검량 선의 기울기를 이용한 계산법을 바탕으 로 계산 하였고 계산식은 LOD (limit of detection) $=3.3 * \sigma / \mathrm{S}$ 이다. 정량 한계는 검량선에 근거한 표준 편차와, 검량선의 기 울기를 이용한 계산법을 바탕으로 계산하였고 계산식은 $\mathrm{LOQ}$ (limit of quantification) $=10 * \sigma / \mathrm{S}$ 이다. 검출 한계와 정량 한계의 $\sigma$ 는 반응의 표준편차를, $\mathrm{S}$ 는 검량 선의 기울기를 말한다. 시료 잔류는 표준 용액에서 blank로 오염되는 시료 잔류의 경우 $0.002 \%$ 이하 기준으로 본 시험에서는 보이지 않았다(Table 1).
(A)

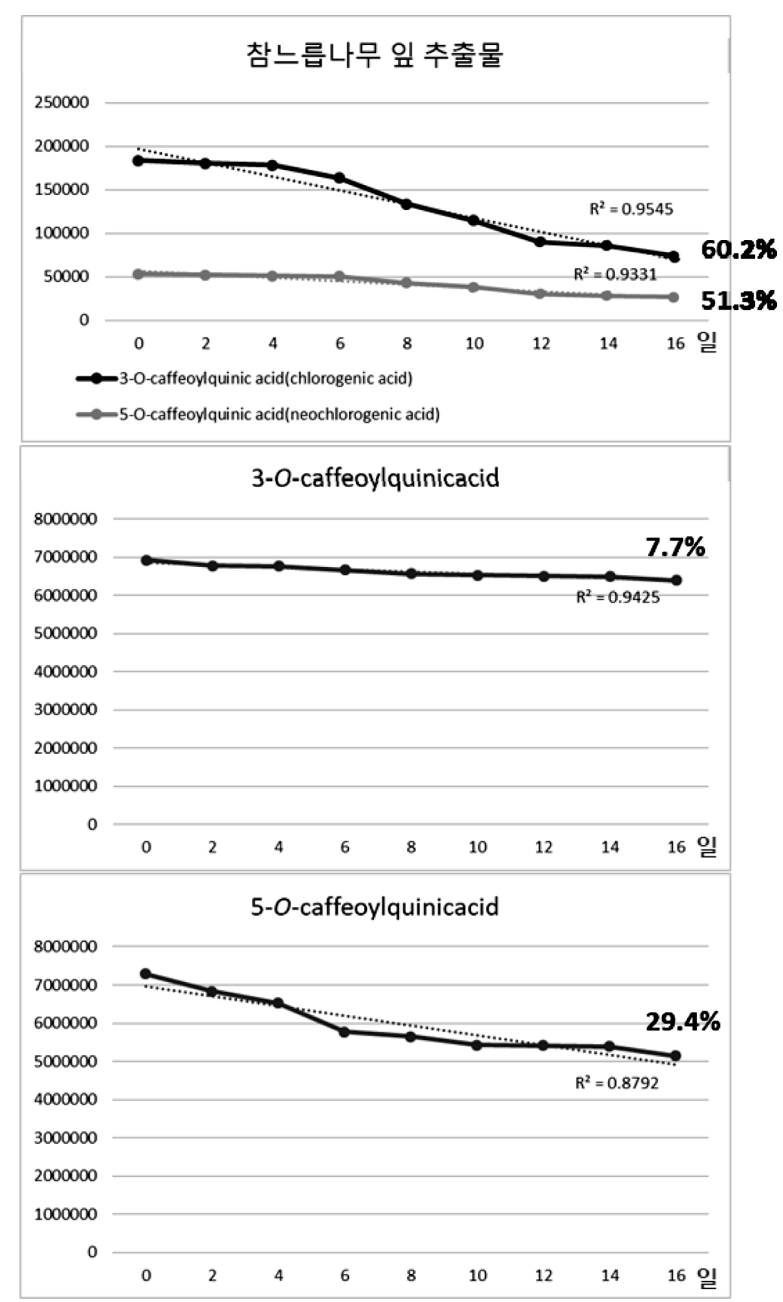

Fig. 3 Temperature storage stability results. (A) 3-O-caffeoylquinic acid and 5-O-caffeoylquinic acid contained in Ulmus parvifolia leaves extract. (B) Two standard compounds, 3-O-caffeoylquinic acid and 5-Ocaffeoylquinic acid

\section{장기 보존 안정성 실험 결과}

$25,40 \%$ 의 상대습도 조건에서 $0,1,3,6$ 개월마다 분석을 진행 하였고 느릅나무 잎 추출물에 포함된 3-O-caffeoylquinic acid와 5-O-caffeoylquinic acid 지표 물질의 함량은 반복 수의 평균으 로 계산하였을 때 감소하지 않고 유지되었고 표준 물질인 두 성분 모두 3 개월까지 각각 $1.5,0.2 \%$ 감소로 큰 변화를 보이지 않았지만 마지막 6 개월에 $5.9,18.0 \%$ 가 감소하여 감소폭이 커 지는 경향을 나타내었다(Fig. 2). 
(A)

(B)
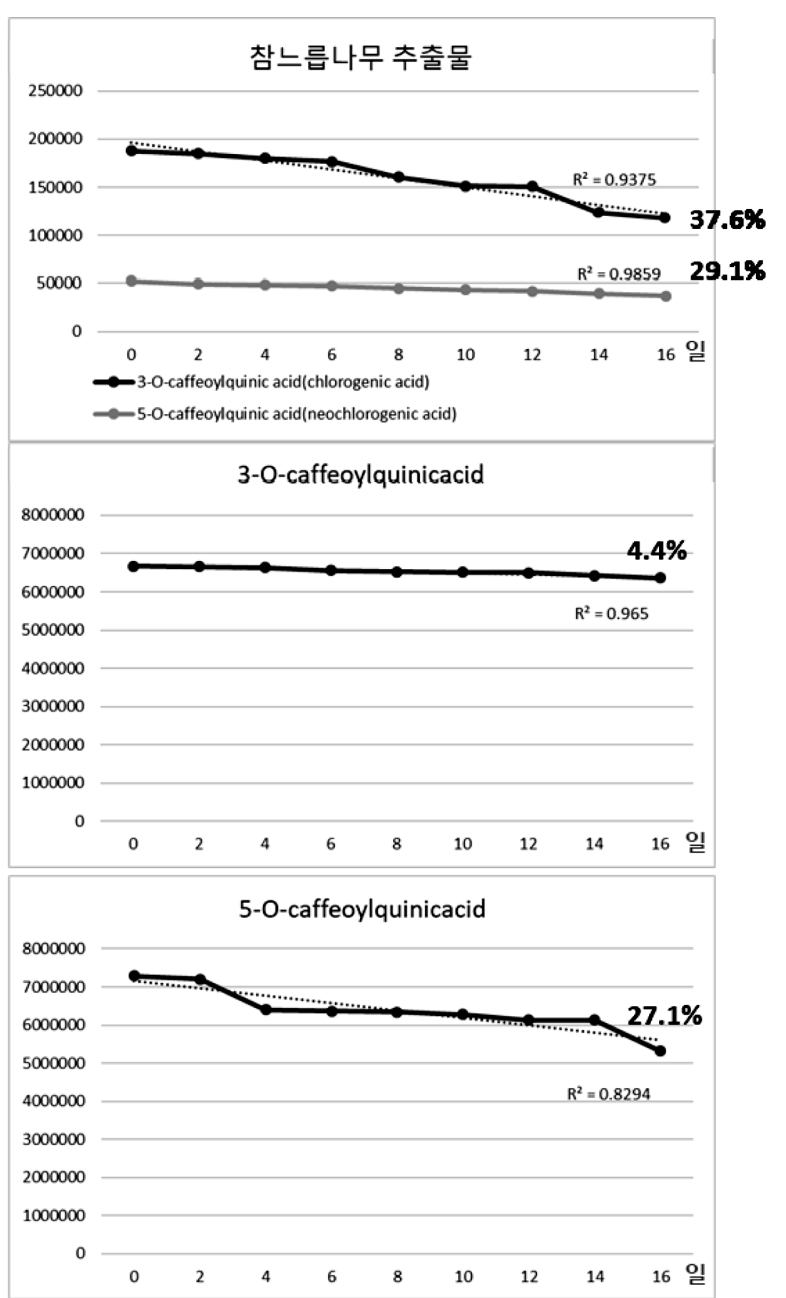

Fig. 4 Light storage stability results. (A) 3-O-caffeoylquinic acid and 5$O$-caffeoylquinic acid contained in Ulmus parvifolia leaves extract. (B) Two standard compounds, 3-O-caffeoylquinic acid and 5-Ocaffeoylquinic acid

\section{가혹 조건 온도 안정성 시험 결과}

느릅나무 잎 추출물을 온도 70 의 조건에서 2 일 간격으로 16 일 동안 총 8 회의 분석을 실시하였으며, 분석결과 느릅나무 잎 추 출물에 포함된 3-O-caffeoylquinic acid는 $60.2 \%$ 감소하였고, 5 $O$-caffeoylquinic acid는 $51.3 \%$ 감소하였다. 표준 물질인 3-Ocaffeoylquinic acid는 $7.7 \%$ 감소하였고 5-O-caffeoylquinic acid 는 $29.4 \%$ 가 감소하였다. 느릅나무 잎 추출물 보다 표준물질의 감소 폭이 상대적으로 적게 나타났다(Fig. 3).

\section{가혹 조건 광선 안정성 시험 결과}

느릅나무 잎 추출물을 직사광선에 노출시킨 후 2 일 간격으로 16 일 동안 총 8 회의 분석을 실시하였으며 분석결과 느릅나무 잎 추출물에 포함된 3-O-caffeoylquinic acid는 $37.6 \%$ 감소하였 고, 5-O-caffeoylquinic acid는 $29.1 \%$ 감소하였다. 표준 물질인 3-O-caffeoylquinic acid는 $4.4 \%$ 감소하였고 5-O-caffeoylquinic acid는 $27.1 \%$ 가 감소하였다(Fig. 4). 느릅나무 잎 추출물 보다
표준물질의 감소 폭이 상대적으로 적게 나타났다. 느릅나무 잎 추출물의 장기 보존 안정성 시험 및 가혹 조건 실험의 결과에 따르면 느릅나무 잎 추출물의 3-O-caffeoylquinic acid, 5-Ocaffeoylquinic acid는 직사광선이 닿지 않는 상온조건에서는 3 개월까지 일정한 함량을 유지할 수 있는 것으로 확인되었다. 3 개월 이후에는 지표 성분이 비교적 큰 폭으로 감소하나, 그 감 소폭이 일반적 함량 기준인 $80-120 \%$ 이내이므로 직사광선이 닿 지 않는 상온조건에서는 6 개월까지 $80 \%$ 이상의 함량으로 보관 이 가능할 것으로 확인 되었다. 특히, 잎 추출물은 고온이나 직 사광선에 노출되는 경우 급격한 감소세를 보이며, 단기간에 함 량 기준에 미달하게 되므로 함유량을 안정적으로 유지하기 위 해서는 고온과 직사광선에 노출되는 환경은 피해야 할 것으로 사료 된다.

결론적으로 느릅나무 잎의 지표성분으로 선정된 3-O-caffeoylquinic acid (chlorogenic acid)와 5-O-caffeoylquinic acid (neochlorogenic $\mathrm{acid})$ 는 추출물에 함유된 성분으로 확인되었고, 유효성이 검정된 UPLC-PDA 크로마토그램을 통해 장기 보존과 가혹 조건 안정 성 평가결과, 느릅나무 잎 추출물은 다양한 성분들이 혼합된 상 태이지만 단일성분보다 안정성이 취약하여 장기 보존과 가혹 조 건에서 급격히 감소하는 경향이 나타났다. 이전의 유사한 결과 에 따르면 caffeoylquinic acids는 온도, 광, 용매 등의 다양한 조건에서 구조적 차이에 따라 안정성에 차이가 있음을 보였고 이는 분해 또는 $c i s$ 로 입체 이성질체화 등으로 변화되어 안정 성이 떨어지는 경향을 나타내었다[22-24]. 또한 2종의 지표 성 분의 안정성을 비교할 경우 상대적으로 3-O-caffeoylquinic acid 가 보다 뛰어난 것으로 확인되었고 이러한 결과는 느릅나무 잎 추출물의 장기 보존과 가혹 조건 안정성 평가에서 5-Ocaffeoylquinic acid 보다 3-O-caffeoylquinic acid 가 손실이 적 은 것으로 나타났기 때문이다. 따라서 느릅나무 잎 추출물 상 업적 활용성을 높이기 위해서는 3-O-caffeoylquinic acid의 함량 을 높이는 재배법과 수확 시기 등을 고민해볼 필요가 있다.

\section{초 록}

Ulmus parvifolia 잎의 약리학적 지표 성분을 제시하기 위해 간 단하고 신뢰할 수 있는 HPLC 분석방법을 개발하였다. 지표 성 분들은 NMR 및 UPLC-QTof-MS 분석에 의해 neochlorogenic acid (trans-5-O-caffeoylquinic acid, 5-CQA)과 chlorogenic acid (trans-3-O-caffeoylquinic acid, 3-CQA)로 구조 동정 되었 다. HPLC를 이용하여 두개 화합물을 포함한 잎 추출물의 정성 /정량 분석 방법을 평가하였다. 잎 $30 \%$ 에탄올 추출물과 지표 성분의 안정성 테스트는 6 개월 동안 평가되었다. 그러나 안정 성 조사 기간 동안 추출물과 지표 성분들 각각의 함량에 대한 유의한 변화는 관찰되지 않았다.

Keywords 안정성 · Caffeoylquinic acid · Ulmus parvifolia leaves · Ultra high performance liquid chromatography

감사의 글 본 연구는 개방형혁신바우처사업(P0010687) 및 농촌진흥청 연 구사업 (세부과제번호: PJ01420404)의 지원에 의해 수행되었습니다. 


\section{References}

1. Kunle OF, Egharevba HO, Ahmadu PO (2012) Standardization of herbal medicines-A review. Int J Biodivers Conserv 4(3): 101-112

2. Yuk HJ, Ryu HW, Kim DY, Park MH, Seo WD, Jeong SH, Oh SR (2019) Comparison of flavonoid and policosanol profiles in Korean winter-spinach (Spinacia oleracea L.) cultivated in different regions. Food Chem 279: 202-208

3. Bauer R (1998) Quality criteria and standardization of phytopharmaceuticals: Can acceptable drug standards be achieved. Drug information journal: DIJ/Drug Information Association, 32(1): 101-110

4. Kim SH, Choi EJ, Kim DH, Lee KY, Lee M, Baek SW, Kwak SJ, Kang TS, Kim YC Sung SH (2008) Stability test of the extracts of Cimicifugae Rhizoma, Achyranthis Radix, Artemisia Capillaris Herba, Moutan Cortex Radicis and Arecae Semen for toxicity study. Kor J Pharmacogn 39: 241-245

5. Keum JH, Han HY, Seok JH, Roh HS, Lee JK, Jeong JY, Kim JA, Woo MH, Choi JS, Min BS (2014) Analysis and stability test of the extracts from Epimedii Herba, Atractylodis Rhizoma Alba and Polygalae Radix for toxicity study. Kor J Pharmacogn 45(2): 135-140

6. Choi SY, Lee S, Choi WH, Lee Y, Jo YO, Ha TY (2010) Isolation and anti-inflammatory activity of bakuchiol from Ulmus davidiana var. japonica. J Med Food 13(4): 1019-1023

7. Lee GY, Jang DS, Kim J, Kim CS, Kim YS, Kim JH, Kim JS (2008) Flavan-3-ols from Ulmus davidiana var. japonica with inhibitory activity on protein glycation. Planta Med 74(15): 1800-1802

8. Kim JP, Kim WG, Koshino H, Jung J, Yoo ID (1996) Sesquiterpene $O$ naphthoquinones from the root bark of Ulmus davidiana. Phytochemistry, 43(2): $425-430$

9. Lee MK, Sung SH, Lee HS, Cho JH, Kim YC (2001) Lignan and neolignan glycosides from Ulmus davidiana var. japonica. Arch Pharm Res 2001(24):198-201

10. Kim YC, Lee MK, Sung SH, Kim SH (2007) Sesquiterpenes from Ulmus davidiana var. japonica with the inhibitory effects on lipopolysaccharide-induced nitric oxide production. Fitoterapia, 2007(78):196-199

11. Jung MJ, Heo SI, Wang MH (2010) HPLC analysis and antioxidant activity of Ulmus davidiana and some flavonoids. Food Chem 120 (1): 313-318

12. Mina SA, Melek FR, Adeeb RM, Hagag EG (2016) LC/ESI-MS/MS profiling of Ulmus parvifolia extracts and evaluation of its antiinflammatory, cytotoxic, and antioxidant activities. Z Für Naturforschung C 71 (11-12): 415-421

13. Kim SP, Lee SJ, Nam SH, Friedman M (2016) Elm tree (Ulmus parvifolia) bark bioprocessed with mycelia of Shiitake (Lentinus edodes) mushrooms in liquid culture: Composition and mechanism of protection against allergic asthma in mice. J Agric Food Chem 64 (4): 773-784

14. Hamed MM, El-Amin SM, Refahy LA, Soliman ESA, Mansour WA, Taleb HMA, Morsi EA (2015) Anticancer and antiviral estimation of three Ulmus pravifolia extracts and their chemical constituents. Orient $\mathrm{J}$ Chem 31(3): 1621

15. Irfan M, Kwon HW, Lee DH, Shin JH, Yuk HJ, Kim DS, Hong SB, Kim SD, Rhee MH (2020) Ulmus parvifolia modulates platelet functions and inhibits thrombus formation by regulating integrin $\alpha_{\mathrm{II}} \beta_{3}$ and cAMP signaling. Front Pharmacol 11: 698

16. Wan C, Li S, Liu L, Chen C, Fan S (2017) Caffeoylquinic acids from the aerial parts of Chrysanthemum coronarium L.. Plants 6(1): 10

17. Mina SA, Melek FR, Adeeb RM, Hagag EG (2016) LC/ESI-MS/MS profiling of Ulmus parvifolia extracts and evaluation of its antiinflammatory, cytotoxic, and antioxidant activities. Z Naturforsch C 71(11-12): 415-421

18. Ma Q, Wei R, Shang D, Sang Z, Liu W, Cao Z (2019) Hepatoprotective and neuroprotective flavanes from the fruits of Ulmus pumila $L$. (Ulmaceae). Pak J Pharm Sci 32(5): 2059-2064

19. Gu ZY, Feng CY, Li SS, Yin DD, Wu Q, Zhang L, Wang LS (2019) Identification of flavonoids and chlorogenic acids in elm fruits from the genus Ulmus and their antioxidant activity. J Sep Sci 42(18): 2888-2899

20. Muhammad N, Veghar H, Muhammad A, Asghar AK, Ghulam JK, Muhammad S, Fawwad A, Daryoush B, Xia FF, Faezeh MG, Li WH, Zhou XH (2018) Chlorogenic acid (CGA): A pharmacological review and call for further research. Biomed Pharmacother 97: 67-74

21. Jesús SG, Luis CZ, Daniel AJV (2017) Chlorogenic acid: Recent advances on its dual role as a food additive and a nutraceutical against metabolic syndrome. Molecules 22(3): 358

22. Xue M, Shi H, Zhang J, Liu QQ, Guan J, Zhang JY, Ma Q (2016) Stability and degradation of caffeoylquinic acids under different storage conditions studied by high-performance liquid chromatography with photo diode array detection and high-performance liquid chromatography with electrospray ionization collision-induced dissociation tandem mass spectrometry. Molecules 21(7): 948

23. Dawidowicz AL, Typek R (2011) The influence of $\mathrm{pH}$ on the thermal stability of 5-O-caffeoylquinic acids in aqueous solutions. Eur Food Res Technol 233(2): 223-232

24. Dawidowicz AL, Typek R (2010) Thermal stability of 5-O-caffeoylquinic acid in aqueous solutions at different heating conditions. J Agric Food Chem 58(24): 12578-12584 